\title{
Late neurocognitive effects in children and adolescents who have undercone oncological treatment: A rehabilitation model
}

\author{
Simona Masneri ${ }^{1}$, Tiziana Bolis ${ }^{2}$ \\ 1. Psychoterapist behavioral-cognitive, Paediatric Haematology-Oncology Unit (ABE Associazione Bambino Emopatico), \\ Spedali Civili BRESCIA, Italy. 2. Psychoterapist aiPSIon onlus (The Italian Association of Psychologists Working in \\ Oncology), Erba (Como), Italy
}

Correspondence: Simona Masneri. Address: Psychoterapist behavioral-cognitive, Paediatric Haematology-Oncology Unit, Spedali Civili BRESCIA, Italy. Email: simona.masneri@virgilio.it

Received: June 3, 2012

DOI : $10.5430 /$ jst.v3n1p29

Accepted: December 2, 2012

URL: http://dx.doi.org/10.5430/jst.v3n1p29
Online Published: December 19, 2012

\begin{abstract}
Oncologists have been driven to face the need to reach their primary goal of patient recovery by reducing or preventing as much as possible late effects in cancer survivors of developmental age as a result of improved oncological treatments, increased survival rates, and their awareness that they are acting in a crucial phase of life. Late effects involve various systems of individual functioning: cardiovascular, respiratory, reproductive and neurocognitive. The aim of this study was to draw attention to late cognitive effects and underline the importance and usefulness of rehabilitation interventions in reducing not only learning difficulties, but also the problems related to socialisation and psychological unease. Neurocognitive outcomes are influenced by the type of cancer treatment, the time that has passed since its administration, surgery, tumour location, and the patient's age and gender. Late effects are generally more severe in cases of radiotherapy, which seems to affect IQ, whereas chemotherapy only seems to affect neuropsychological abilities such as attention, concentration, memory, and executive and visuo-spatial functions. Cognitive outcomes therefore affect not only intellectual and educational functioning, but also social and psychological functioning.

It is widely acknowledged that Butler and Copeland's tripartite Cognitive Remediation Program (CRP) can benefit children and adolescents with neurocognitive difficulties due to oncological treatment. It not only improves attention and learning abilities, but also the ability to manage post-treatment cognitive dysfunction more effectively.
\end{abstract}

\section{Key words}

Late neurocognitive effects, Oncological treatment, Cognitive Remediation Program (CRP)

\section{I ntroduction}

In the European Union (E.U.), the incidence of cancer in children aged 0-14 years was 138.5 cases per million per year during the period 1978-1997. This means that in the E.U. on average every year cancer was diagnosed in about 13,000 children. Specifically, cancer incidence was lowest in the British Isles (UK and Ireland, 131.5 cases per million children per year) and highest in Finland (173.2 cases per million children per year). Leukaemia was the most common type of cancer. Its incidence was significantly highest in the North and the South of Europe (Italy, Malta, Slovenia, Spain, Turkey) 
and lowest in the East (Belarus, Estonia, Hungary, Slovakia). The second form of cancer was brain and spinal neoplasms, accounting for $22 \%$ of the total incidence overall and being highest in the North and East and lowest in the West of Europe (France, Germany, Netherlands, Switzerland). The third most common type of cancer was represented by lymphomas (11\%), which were significantly more frequent than average in the South and East of Europe, and significantly less frequent in the British Isles ${ }^{[1]}$.

On the contrary, In Italy, the annual incidence of paediatric tumours was 175.4 cases per million per year in the period 1998-2002, which was slightly higher than detected in the nineties in the United States and also in Europe ${ }^{[2]}$. Fortunately, these tumours have a good prognosis both during childhood and adolescence ${ }^{[2]}$, in line with the literature data ${ }^{[3]}$.

In Italy, the survival rate for leukaemia in the $0-14$ years age group was $84 \%$, and $71 \%$ in adolescents. Cancers of the central nervous system appear more aggressive, with a survival rate of $61 \%$ in children and $72 \%$ in adolescents; however, the difference is not statistically significant ${ }^{[4]}$.

According to data from the literature, the most widespread paediatric cancers are represented by lymphomas and acute lymphoblastic leukaemia (ALL) of the central nervous system (CNS), accounting for $50 \%$ of all paediatric cases ${ }^{[5,8]}$. Five-year survival rate is $93 \%$ in the case of posterior fossa tumours ${ }^{[6]}$, Wilms' tumours ${ }^{[7]}$ and Hodgkin's lymphoma ${ }^{[7]}$, and $65 \%$ in the case of medulloblastomas ${ }^{[9]}$, while it is only $10 \%$ in intrinsic brainstem gliomas ${ }^{[9]}$. However, although these data show that oncological treatments may fortunately cure children and adolescents, we must remember that they do not assure the complete absence of negative effects, including the so called "late effects". The latter are chronic or progressive conditions that involve different apparatus, mainly the cardiovascular, respiratory, reproductive and neurocognitive systems ${ }^{[10]}$. Moreover, Gross-King et al. showed that $40 \%-100 \%$ of cancer survivors are affected by cognitive difficulties ${ }^{[5]}$. The aim of this brief report is to underline the need of a rehabilitation treatment in order to reduce the possible unease caused by learning difficulties and socialisation discomfort. It also proposes to improve attention and learning performance adopting Butler and Copeland’s Cognitive Remediation Program (CRP).

\section{Late neurocognitive effects on personal areas}

In 1975, Soni et al. showed that brain radiotherapy (24 Gy) did not affect the intellectual functioning of treated children. Indeed, the sample submitted to radiotherapy was small (14 children treated by CNS irradiation for ALL compared with 19 children with solid tumours treated by irradiation to other sites, and assessed before irradiation and then over an 18-month period), and that the patients treated were significantly younger than controls ${ }^{[11]}$. On the other hand, Meadows et al. ${ }^{[11]}$ showed a cognitive deterioration ${ }^{[11,12]}$. Other, subsequent studies confirmed the negative effects of brain radiotherapy on cognitive status in treated children and adolescents ${ }^{[10,13]}$. In particular, Mulhern et al. showed a 12-14 point reduction in IQ (intelligence quotient) ${ }^{[14]}$. This data has been confirmed by Palmer et al. describing a neurocognitive decline in children treated for medulloblastoma associated with radiotherapy. Moreover, children aged less than eight years old treated with a standard dose (36 Gy) had more severe neurocognitive outcomes than older children receiving a lower dose (23 Gy) ${ }^{[9]}$. In addition, in survivors of medulloblastoma, a deficit in academic achievement, memory, attention, and processing speed has been evidenced ${ }^{[5,9,10,13,15-17,19,21]}$. Combined radio- and chemotherapy reduced cognitive performances and was associated with memory loss, concentration, and learning problems ${ }^{[5,13-16,18]}$. The most commonly affected neurocognitive functions were loss of attention and concentration ${ }^{[9,10,19,21]}$, and memory problems ${ }^{[5,13,19]}$, in particular working memory ${ }^{[10,22]}$; also the visuo-motor integration and visuo-spatial abilities ${ }^{[5,9,20,21,23-25]}$, executive and verbal functions ${ }^{[13,14,20]}$, speed of execution ${ }^{[13,20]}$, and problem-solving abilities were affected ${ }^{[20]}$. On the other hand, chemotherapy alone did not reduce total IQ ${ }^{[16,17]}$, but was found to affect the neuropsychological abilities that are essential in a number of learning domains and intelligence tests ${ }^{[7,8,20,24,23]}$. The involvement of certain neuropsychological abilities seems to be due to a reduction in the volume of the white matter in the right frontal lobe ${ }^{[16]}$. 
The data obtained by Voxel-based morphometry (VBM) studies showed that this is significant in adolescents and children treated for lymphoblastic leukaemia, who mainly have difficulties in tests of attention, visual construction, mental flexibility and mathematics, reading, the production of written language ${ }^{[26]}$, and in the behavioural sphere ${ }^{[19,24-26]}$.

When the children and adolescents return to school after treatment, they have to handle their difficulties in attention and concentration, as well as show the self-regulation of cognition and behaviour. Furthermore, the reaction of their teachers and in particular of peers can lead to antisocial behaviour ${ }^{[27]}$. Difficulties in attention, concentration and executive functions will affect the learning process, but they are certainly the basis of disruptive behaviour disorders (e.g. ADHD). Thus, when children and adolescents come back to school after treatment, they must learn to manage their attention and concentration difficulties, their behavioural and cognitive autoregulation and respond to potential adverse reactions of teachers and peers in their response to behavioural dysregulation. Adolescent survivors of acute lymphoblastic leukaemia, CNS tumours and neuroblastoma are at an increased risk of depressive symptoms, anxiety (internalising symptoms), attention deficit disorder, and antisocial behaviour for reduced social competence (externalising symptoms). The history of all CNS tumours and neuroblastoma may therefore increase the risk of adverse behavioural and social consequences. Treatments with cranial radiation and/or intrathecal methotrexate were specific risk factors ${ }^{[27]}$. Learning and concentration difficulties, together with school absences, poor performance, and emotional and behavioural problems can make it difficult to re-enter everyday life. In the presence of one or more of these factors, the American school system provides for the activation of Special Educational Services. One study of long-term survivors showed that 23\% of the 12,430 subjects enrolled had needed Special Educational Services for periods ranging from 4.8 years (chemotherapy) to 5.8 years (high-dose radiotherapy) ${ }^{[7]}$. Radiotherapy alone or in combination with chemotherapy significantly increased the likelihood of being included in a Special Educational Services programme ${ }^{[7]}$.

For these reasons, research and clinical experience have stressed the need for interventions aimed at rehabilitating the patient, and clinicians have gradually modified their treatment protocols: radiotherapy has much more aggressive effects on neurocognitive functions than chemotherapy ${ }^{[10,13]}$.

\section{Butler and Copeland's Cognitive Remediation Program (CRP): A rehabilitation model}

The aim of Butler and Copeland's tripartite rehabilitation model is to treat children and adolescents who present neurocognitive deficits after being treated for all type of cancers, and in particular brain tumours.

The model is called "tripartite" because it combines neuropsychological rehabilitation with educational and clinical psychology ${ }^{[9,11]}$. The first level of intervention concerns the neuropsychological rehabilitation of attention, adopting Solbherg and Matter's exercises brought together in an attention process training (APT). This programme stimulates the selective, sustained, divided and executive control of attention ${ }^{[9,11]}$. The second level uses educational psychology techniques to teach the patients meta-cognitive strategies that can be used before, during and after tasks requiring attention, with the aim of improving the self-regulation of attention and memory, and therefore performance ${ }^{[9,11]}$.

The third level uses the stress inoculation training (SIT) in order to improve the psychological management of the difficulties that need to be faced. In this phase, motivation towards effort is supported by improving the patients' awareness of their difficulties, in order to favour a positive and optimistic attitude ${ }^{[9,11]}$. The most extensively used cognitive-behavioural techniques are internal dialogue, reinforcement and modelling ${ }^{[9]}$, but it also allows the use of additional sessions for the children/adolescents who present symptoms of anxiety and depression.

The CRP has a total duration of 50 hours divided into two-hour sessions; 15 minutes being dedicated to attention rehabilitation (APT) and the remaining time to the acquisition of meta-cognitive strategies and SIT. The CRP involves 
team work, in which the children/adolescents and their therapists work together with the patients' teachers and families in order to improve the generalisation of academic functioning ${ }^{[9,11]}$.

Many studies of the efficacy of CRP indicate that it significantly increases selective attention, and attention and concentration in the school performance (language and mathematics), but not working memory, memory recall or vigilance $^{[9,11,28]}$.

\section{Conclusions}

In conclusion, paediatric oncological treatments may have neurocognitive consequences that negatively affect the academic performances, emotional state (depression, anxiety) and behaviour of patients. Moreover, school attendance may be interrupted for long periods by hospitalisations or pathologies like minor infections. As Eiser et al. evidenced, frequent absences from school affect a child's school career, relationships with teachers, and their perception of the acceptance of their peers. The disease experience can also lead to changes in their physical appearance and character. All of these alterations can feed a sense of isolation that may reduce the sense of belonging and involvement in school activities ${ }^{[28]}$. Rehabilitating such neuropsychological and cognitive outcomes is essential, first of all to improve cognitive functions, but also to prevent uneasiness in the social and psychological domains. A rehabilitation programme such as that proposed by Butler and Copeland involves the collaborative effort of the most important figures in the lives of the children/adolescents and, by acting at many levels, responds to many of the difficulties due to the cancer treatments. It acts on fundamental dimensions of the quality of life, such as social, cognitive and emotional functioning, and not only offers the possibility of completing an educational career that will have a major bearing on the children's and adolescents' future choices, but also the possibility of leading an autonomous life as it facilitates reintegration into the world beyond the family and hospitalisation, as well as the construction of significant peer relationships.

\section{References}

[1] K. Pritchard-Jones, P. Kaatsch, E. Steliarova-Foucher, C.A. Stille, Cancer in children and adolescents in Europe: Developments over 20 years and future challenges, European Journal of Cancer. 2006; 42(13): 2183-2190. PMid:16919780 http://dx.doi.org/10.1016/j.ejca.2006.06.006

[2] Rapporto Airtum. Tumori infantili. Incidenza, sopravvivenza, andamenti temporali (Airtum, report.Childhood cancer. Incidence, survival, time trends) [Internet]. (2008). Available from: www.registro tumori.it

[3] Mody R, Li S, Dover DC, Sallan S, Leisenring W, Oeffinger KC, Yasui Y, Robison LL, Neglia JP. Twenty-five-year follow-up among survivors of childhood acute lymphoblastic leukaemia: a report from the Childhood Cancer Survivor Study. Blood. 2008; 111: 5515-23. PMid:18334672 http://dx.doi.org/10.1182/blood-2007-10-117150

[4] Rapporto AIRTUM 2010. La prevalenza dei tumori in Italia. Persone che convivono con il tumore, lungospravvienti e guariti. Cancer prevalence in Italy. Patients living with cancer, long-term survivors and cured patients [Internet]. Available from: www.airtum.it

[5] Gross-King M, Booth-Jones M, Couluris M. Neurocognitive impairment in children treated for cancer: how do we measure cognitive outcome? J Pediatr Oncol Nurs. 2008; 25: 227-32. PMid:18559886 http://dx.doi.org/10.1177/1043454208321114

[6] Vaquero E, Gómez CM, Quintero EA, González-Rosa JJ, Márquez J. Differential prefrontal-like deficit in children after cerebellar astrocytoma and medulloblastoma tumour. Behav Brain Funct. 2008; 4: 18. PMid:18412947 http://dx.doi.org/10.1186/1744-9081-4-18

[7] Mitby PA, Robison LL, Whitton JA, Zevon MA, Gibbs IC, Tersak JM, Meadows AT, Stovall M, Zeltzer LK, Mertens AC. Utilisation of special education services and educational attainment among long-term survivors of childhood cancer: a report from the Childhood Cancer Survivor Study. Cancer. 2003; 97: 1115-26. PMid:12569614 http://dx.doi.org/10.1002/cncr.11117

[8] Bhatia S. Cancer Survivorship-Paediatric Issues [Internet]. Haematology Am SocHematol Educ Program. 2005; 507-15. Available from: http: //store.hematology.org/ASHStore/AllProducts/tabid/177/Category/EDUPROGRAMBOOK/Default.aspx

[9] Butler RW, Mulhern RK. Neurocognitive interventions for children and adolescents surviving cancer. J Pediatr Psychol. 2005; 30: 65-78. http://dx.doi.org/10.1093/jpepsy/jsi017 
[10] Mulhern RK, Phipps S, White H. Neuropsychological outcome. In Wallace H, Green D. Late effects of childhood cancer. London: Arnold Publication. 2004; 18-33.

[11] Butler RW, Sahler OJZ, Askins MA, Alderfer MA, Katz ER, PhippsS, Noll RB. Intervention to improve neuropsychological functioning in childhood cancer survivors. Dev Disabil Res Rev. 2008; 14: 251-8. PMid:18924157 http://dx.doi.org/10.1002/ddrr.33

[12] Eiser.C and Lansdown.R, Retrospective study of intellectual development in children treated for acute lymphoblastic leukaemia, Archives of Disease in Childhood. 1977; 52: 525-529; adc.bmj.com on August 11, 2012 - Published by group.bmj.com.

[13] Alvarez JA, Scully RE, Miller TL, Daniel Armstrong F, Constine LS, Friedman DL, Lipshultz SE. Long-term effects of treatments for childhood cancers. Haematology and Oncology Curr Opin Pediatr. 2007; 19: 23-31.

[14] Palmer SL, Reddick WE, Gajjar A. Understanding the cognitive impact on children who are treated for medulloblastoma. J Pediatr Psychol. 2007; 32: 1040-9. PMid:17329318 http://dx.doi.org/10.1093/jpepsy/jsl056

[15] Rodgers J, Britton PG, Morris RG, Kernahan J, Craft AW. Memory after treatment for acute lymphoblastic leukaemia. Arch Dis Child. 1992; 67: 266-8. PMid:1575545 http://dx.doi.org/10.1136/adc.67.3.266

[16] Appleton RE, Farrell K, Zaide J, Rogers P. Decline in head growth and cognitive impairment in survivors of acute lymphoblastic leukaemia. Arch Dis Child. 1990; 65: 530-4. PMid:2357094 http://dx.doi.org/10.1136/adc.65.5.530

[17] Smibert E, Anderson V, Godber T, Ekert H. Risk factors for intellectual and educational sequelae of cranial irradiation in childhood acute lymphoblastic leukaemia. Br J Cancer. 1996; 73: 825-30. PMid:8611389 http://dx.doi.org/10.1038/bjc.1996.145

[18] Anderson V, Smibert E, Ekbert H, Godber T. Intellectual, educational, and behavioural sequelae after cranial irradiation and chemotherapy. Arch Dis Child. 1994; 70: 476-83. PMid:8048815 http://dx.doi.org/10.1136/adc.70.6.476

[19] Carey MW, Haut SL, Reminger JJ, Hutter R, Theilmann KL, Kaeming K. Reduced frontal white matter volume in long-term childhood leukaemia survivors: A voxel-based morphometry study, AJNR Am J Neuroradiol. 2008 Apr; 29(4): $792-7$. PMid:18184841 http://dx.doi.org/10.3174/ajnr.A0904

[20] Lofstad GE, Reinfjell T, Hestad K, Diseth TH. Cognitive outcome in children and adolescents treated for acute lymphoblastic leukaemia with chemotherapy only. Acta Paediatr. 2009; 98: 180-6. PMid:18826490 http://dx.doi.org/10.1111/j.1651-2227.2008.01055.x

[21] Eiser C. Cognitive deficits in children treated for leukaemia. Arch Dis Child. 1991; 66: 164-8. PMid:1899787 http://dx.doi.org/10.1136/adc.66.1.164

[22] Kirschen MP, Davis-Ratner MS, Milner MW, Annabel SH, Chen Sha, Schraedley-Desmond P, Fisherc PG, Desmondg JE. Verbal memory impairments in children after cerebellar tumour resection. Behav Neurol. 2008; 20: 39-53. PMid:19491473

[23] Lafay-Cousin L, Bouffet E, Hawkins C, Amid A, Huang A, Mabbot DJ. Impact of radiation avoidance on survival and neurocognitive outcome in infant medulloblastoma. Curr Oncol. 2009; 16: 21-8.G Ital Med Lav Erg. 2011; 33:1, Suppl A, Psicol

[24] von Hoff K, Kieffer V, Habrand JL, Kalifa C, Dellatolas G, Grill J. Impairment of intellectual functions after surgery and posterior fossa irradiation in children with ependymoma is related to age and neurologic complications. BMC Cancer. 2008; 8:15. PMid:18208613 http://dx.doi.org/10.1186/1471-2407-8-15

[25] Moore BD. Neurocognitive outcomes in survivors of childhood cancer. J Pediatr Psychol. 2005; 30: 51-63. PMid:15610985 http://dx.doi.org/10.1093/jpepsy/jsi016

[26] Buizer AI, de Sonneville LMJ, van den Heuvel-Eibrink MM, Veerman AJP. Behavioural and educational limitations after chemotherapy for childhood acute lymphoblastic leukaemia or Wilms tumour. Cancer. 2006; 106: 2067-75. PMid:16568441 http://dx.doi.org/10.1002/cncr.21820

[27] Schultz KAP, Ness KK, Whitton J, Recklitis C, Zebrack B, RobinsLL, Zeltzer L, Mertens AC. Behavioural and social outcome in adolescent survivors of childhood cancer: a report from the childhood cancer survivor study. J Clin Oncol. 2007; 25: 3649-56. PMid:17704415 http://dx.doi.org/10.1200/JCO.2006.09.2486

[28] Butler RW, Copeland DR, Fairclough DL, Mulhern RK, Katz ER, Kazak AE, Noll RB, Patel SK. A multicenter, randomized clinical trial of a cognitive remediation program for childhood survivors of a pediatric malignancy. J Consult Clin Psychol. 2008; 76: 367-78. PMid:18540731 http://dx.doi.org/10.1037/0022-006X.76.3.367 